\title{
Paleontological Survey of THe JuRassic MORRISON FORMATION IN DiNOSAUR NATIONAL MONUMENT
}

\author{
GEORGE F. ENGELMANN $\downarrow$ DEPARTMENT OF GEOGRAPHY AND GEOLOGY \\ UNIVERSITY OF NEBRASKA AT OMAHA $\bullet$ OMAHA
}

\section{SUMMARY OF PROJECT TO DATE}

\section{OVERALL PROGRESS}

The paleontological survey of the Morrison Formation within Dinosaur National Monument (DINO) was planned as a three-year project. The objectives of the project have been to exhaustively search the exposures of the Morrison Fm. within DINO for fossil occurrences of any sort and to document in the files of the monument all known and newly discovered localities. This is the third and final year of the project. The work of the previous two years has been described in semiannual and annual reports and summarized in the 14th and 15th Annual Reports of the Research Center (Engelmann 1991, 1992).

During the first field season, a field assistant and I surveyed approximately $40 \%$ of the area of surface exposures of the Morrison Fm. within the boundaries of DINO. This includes exposures east of the Carnegie Quarry/Visitor Center (CQ) along the south side of Split Mountain, at Deerlodge Park and in the headquarters area. One hundred sixty-four paleontological localities were documented in the first year. Most of these were occurrences of dinosaur bone or silicified wood. Approximately one third of the localities recorded had been known prior to the survey. Some of these had never been documented and about forty had been reported in a survey conducted in 1984. The remainder were newly discovered sites.
During the summer of 1991, my field assistant and I inspected all Morrison outcrops within DINO along the north side of Split Mountain. We also inspected exposures along the east side of Rainbow Draw within DINO administrative boundaries but held by the state of Utah, and recorded a few localities just outside DINO boundaries in this area. On the south side of Split Mountain, we began working westward from the CQ but did not get very far in that direction. Altogether, I estimate that approximately $4 \mathrm{~km}^{2}$ of area was surveyed during 1991. The first two years of work covered approximately $75 \%$ of the area to be surveyed.

Within the area covered during the 1991 field season we recorded 109 localities. As in the first year of the survey, most of the localities recorded during the 1991 field season were occurrences of dinosaur bone (present at 74 sites) or silicified wood (present at 33 sites). About ten of these localities can be identified with varying degrees of certainty with sites found by the Milwaukee Public Museum survey conducted in 1984. Several other sites recorded by that survey within the area of our field work were sought but could not be relocated.

During 1992, the final field season, we examined exposures from the CQ westward to the monument boundary. This completes the field work for the survey, as all accessible exposures of the Morrison Fm. within DINO, an area estimated at roughly $8 \mathrm{~km}^{2}$, have been examined at close range for surface occurrences of fossils. Eighty-four 
localities were documented during 1992. Of the 84 sites recorded, dinosaur bone was found at 52 and silicified wood at 19. 6 sites had non-dinosaurian vertebrate remains, 5 were occurrences of invertebrates, and there were 6 sites representing other types of fossil material, carbonized plant, coalified wood or traces. About 8 of the localities could be identified with localities reported by the 1984 survey. There was some difficulty in relocating sites from that survey.

Localities were documented in the same manner throughout the project, by notes written in the field, by location on topographic maps and by photographs of the site and the surrounding area. Unique locality numbers have been assigned and verbal site descriptions have been entered into the computerized locality files at DINO. A small number of specimens were collected and have been cataloged and deposited in the collections at DINO. One variation on the general procedure described above that was attempted during the 1992 field season was the use of the Global Positioning System (GPS) to document localities. A GPS field unit was available to us during this season and as a small pilot project we logged about 30 selected localities as GPS files.

\section{SIGNIFICANT FINDINGS}

The area surveyed during the final field season was much like that surveyed during the first year, in that all of the members of the Morrison Fm. were well exposed within the outcrop area. Indeed, the area west of the CQ is a continuation of outcrop surveyed during the first year and is exposed in much the same way. In contrast, as noted in previous reports, the area surveyed during the second year was dominated by exposures of the Salt Wash Mbr., as the Brushy Basin Mbr. was poorly exposed or absent over much of the area.

On the whole, the observations made during this field season have continued to corroborate the interpretations derived from the work of the previous years. The nature of the fossil occurrences with respect to abundance, taxonomic representation, preservation, lithologies and stratigraphic distribution were consistent with previous findings.

As noted above, dinosaur bone is quite common within the Morrison Fm., occurring throughout both the Salt Wash and Brushy Basin members. Within the Salt Wash, these occurrences are confined to the sandstone units which dominate that member and which seem to be distinguishable as lower, middle and upper sandstones. Within these sandstone units, prominent, ridgeforming conglomeratic lenses most consistently show surface indications of bone, to the extent that the orange-weathering exposures of this facies virtually always have bone fragments at the surface.

I believe that the explanation for this is that bones and bone fragments were transported and deposited as clasts in these coarse sediments. Consequently, much of the fragmentary bone on the surface is derived from equally fragmentary material in the unweathered rock. The observation of taxonomically-unidentifiable, pebble-sized fragments of bone in place in the conglomerate tends to support this interpretation. In most cases, only a single locality number has been assigned to the entire contiguous exposure area of such horizons rather than recognizing separate localities for each fragment of bone. This was done so that fragmentary material would not inflate locality numbers in a misleading way. On the other hand, not all fragmentary material has such a fragmentary origin. Identifiable single or multiple elements do occur within the conglomeratic horizons and may provide no more surface indication than bone fragments. Only excavation can conclusively determine the extent and condition of the specimen.

Silicified wood is also common in the same Salt Wash sandstone bodies. Wood occurs as logs, which may be quite large, or as small fragments. Preservation varies from coarse replacement that leaves a sugary texture to very fine grained silica that preserves fine structural details.

Coalified wood (and sometimes carbonized bone) is common in these sandstones, and these and other organic concentrations are often associated with or impregnated by gypsum. These occurrences invariably produce a distinctive yellow stain in the sediment on weathering, probably the result of oxidizing reduced iron compounds. The yellow patches are easily recognizable at a considerable distance, revealing the location of the organic concentration and often silicified wood in close association. 
Dinosaur bone and wood are again the commonest fossils in the Brushy Basin Mbr. where they occur within the sandstones, but also in the finer-grained siltstones and mudstones. With the possible exception of the channel sandstone that contains the CQ, no persistent fossiliferous horizons similar to those in the Salt Wash are recognizable. Specimens tend to be isolated occurrences. The bone is often well preserved, sometimes heavily agatized. Wood is usually well preserved with very fine grained silica.

Unlike the Salt Wash, invertebrates (mostly gastropods) and invertebrate traces can be found within the Brushy Basin. Invertebrate localities are not numerous, but specimens may be abundant where they occur. In some cases, gastropods are well preserved, but most often show up at the surface as steinkerns.

Many of the occurrences of dinosaur bone could yield taxonomically identifiable specimens if excavated, and should be inspected more closely on a systematic basis. This is particularly true for the Salt Wash localities because the record for dinosaurs in this unit is relatively poorly known. Well preserved invertebrates and plant specimens are present, and could provide the basis for a useful study.

\section{$\checkmark \quad$ Literature Cited}

Engelmann, George F. 1991. Paleontological survey of the Jurassic Morrison Formation in Dinosaur National Monument. In the 14th Annual Report of the University of Wyoming - National Park Service Research Center. Mark S. Boyce and Glenn E. Plumb, eds. pp. 37-38.

Engelmann, George F. 1992. Paleontological survey of the Jurassic Morrison Formation in Dinosaur National Monument. In the 15th Annual Report of the University of Wyoming - National Park Service Research Center. Glenn E. Plumb, ed. p. 83-84. 